\section{Commentary: Patching holes in the management of postsurgical air leaks}

\author{
Madeline L. Fryer, MMSc, ${ }^{a}$ and \\ Leora B. Balsam, $\mathrm{MD}^{\mathrm{b}}$
}

Persistent air leak (PAL) lasting longer than 5 days remains a dreaded complication of thoracic surgery, especially lung resections. Patients with PAL are at increased risk for infection, issues with mechanical ventilation, and chest tube pain and have higher overall morbidity and mortality, longer duration of hospitalization, and greater resource utilization. ${ }^{1,2}$ Various strategies have been proposed for the prevention and treatment of PAL, including surgical techniques and a variety of biological and synthetic sealants, ${ }^{3}$ but no clear best practice consensus has been reached. Many clinical studies in this area have been hindered by small sample sizes and heterogeneous patient populations.

In this issue of the Journal, Kanzaki and colleagues ${ }^{4}$ evaluate the use of allogeneic cell sheets (CSs) as artificial pleura for the intraoperative treatment of air leaks. This study, performed in a rodent model, builds on their previous work using a similar construct derived from autologous cells in small and large animal models. ${ }^{5,6}$ In brief, the process involves culturing lung-derived cells for several weeks until they can be harvested as an intact sheet with the extracellular matrix. Two sheets are then applied directly onto the lung surface at the site of the air leak for 5 minutes; no additional suturing or sealant devices are required.

The leap from an autologous to an allogeneic substrate is important because it suggests the possibility of an off-theshelf product. As noted by the authors, the need to custommanufacture CSs for each individual patient represents a significant logistic and financial barrier hindering potential

\footnotetext{
From the ${ }^{\mathrm{a} U n i v e r}$ sity of Massachusetts Medical School and ${ }^{\mathrm{b}}$ Division of Cardiac Surgery, UMass Memorial Medical Center, Worcester, Mass.

Disclosures: The authors reported no conflicts of interest.

The Journal policy requires editors and reviewers to disclose conflicts of interest and to decline handling or reviewing manuscripts for which they may have a conflict of interest. The editors and reviewers of this article have no conflicts of interest.

Received for publication Sept 28, 2020; revisions received Sept 28, 2020; accepted for publication Oct 1, 2020; available ahead of print Oct 9, 2020.

Address for reprints: Leora B. Balsam, MD, Division of Cardiac Surgery, UMass Memorial Medical Center, University Campus, 55 Lake Ave North, Worcester, MA 01655 (E-mail: leora.balsam@umassmemorial.org).

JTCVS Techniques 2020;4:343-4

2666-2507

Copyright (C) 2020 The Authors. Published by Elsevier Inc. on behalf of The American Association for Thoracic Surgery. This is an open access article under the CC BY-NCND license (http://creativecommons.org/licenses/by-nc-nd/4.0/).

https://doi.org/10.1016/j.xjtc.2020.10.004
}

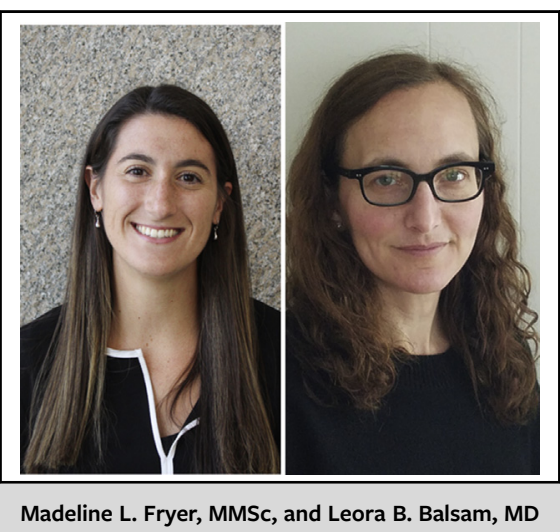

\author{
CENTRAL MESSAGE \\ Cell sheets derived from alloge- \\ neic lung tissue can be used to \\ successfully treat postsurgical air \\ leaks in a rodent model and \\ warrant further preclinical inves- \\ tigation in large animals.
}

widespread use of this technology. Furthermore, it is challenging to predict which patients will develop an intraoperative air leak of sufficient size to warrant immediate intervention beyond routine chest tube placement; an off-the-shelf product that could be used by all would limit waste from custom manufacturing of CSs for patients who do not need them.

Another important consideration with this model is how the host's response to allogeneic tissue affects pleural remodeling. Although previous studies using CSs derived from autologous skin showed mesothelial migration and similar histological morphology as native lung at 3 months, it is reasonable to think that the inflammatory response triggered by nonself antigens would lead to a different type of tissue remodeling. Bioluminescent intensity, which was used as a surrogate for donor cell viability in this study, was reduced at 14 days in recipient rats with competent immune systems, suggesting rejection of allogeneic CSs by the hosts. Reoperation at 28 days found that CSs were tightly adherent to the lung surface without evidence of recurrent air leak, and Azan staining showed significant collagen deposition on the lung surface.

It would be interesting to see further mechanistic studies investigating whether the transplanted CS itself or scar formation in response to foreign material plays a predominant role in sealing off air leaks in this model. This information may be relevant to oncology patients undergoing lung resection whose immune systems and wound healing are weakened by chemotherapy. 
An additional question raised by this report is the potential source of cells for generating CSs. This issue was previously addressed in the group's earlier work that used autologous CSs derived from both lung and skin cells, because the cost and morbidity of skin biopsy is significantly less than that of lung biopsy, but the allogeneic model presented here uses only lung tissue. Another area of concern is how well these CSs will treat air leaks in a larger animal model, given that autologous CSs were previously associated with recurrent air leaks at $>25 \mathrm{~cm} \mathrm{H}_{2} \mathrm{O}$ of airway pressure in swine. ${ }^{6}$ Finally, studies performed thus far have been limited to young animals with healthy lungs; it remains to be seen how emphysematous lungs may affect the efficacy of CSs in treating air leaks.

Although the use of allogeneic CSs is not a silver bullet solution to postsurgical air leaks as currently presented, it remains a promising technology that warrants further preclinical investigation.

\section{References}

1. Bronstein ME, Koo DC, Weigel TL. Management of air leaks post-surgical lung resection. Ann Transl Med. 2019;7:361.

2. Sakata KK, Reisenauer JS, Kern RM, Mullon JJ. Persistent air leak: review. Respir Med. 2018;137:213-8.

3. Sakai T, Matsutani N, Kanai E, Yamauchi Y, Uehara H, Iinuma H, et al. Efficacy of a sheet combined with fibrin glue in repair of pleural defect at the early phase after lung surgery in a canine model. Gen Thorac Cardiovasc Surg. 2018;66:103-7.

4. Kanzaki M, Sekine H, Takagi R, Yamoto M. Bioartificial pleura using allogenic cell sheet for closing of lung air leakage. J Thorac Cardiovasc Surg Tech. 2020; 4:336-40.

5. Kanzaki M, Yamato M, Yang J, Sekine H, Kohno C, Takagi R, et al. Dynamic sealing of lung air leaks by the transplantation of tissue engineered cell sheets. Biomaterials. 2007;28:4294-302.

6. Kanzaki M, Yamato M, Yang J, Sekine H, Takagi R, Isaka T, et al. Functional closure of visceral pleural defects by autologous tissue engineered cell sheets. Eur J Cardiothorac Surg. 2008;34:864-9. 